\title{
INNOVATIONS AS AN IMPORTANT COMPONENT IN THE SYSTEM OF ENVIRONMENTAL SUSTAINABILITY IN THE MANAGEMENT OF THE USE OF RESOURCE POTENTIAL IN THE REGIONS OF UKRAINE
}

\author{
Ihor Zvarych', Olena Zvarych²
}

\begin{abstract}
This article highlights the impact of innovation on achieving environmental sustainability of regional economic systems in the context of effective management of significantly limited natural resources in modern Ukraine, which was the subject of the study, its key objective and main task. Methodology. The proposed work uses systemic and synergetic approaches, methods of analysis and synthesis, induction and deduction, historical and comparative analysis, etc. Value/originality. Consideration of the issues of regional innovation and environmental sustainability of regional economic systems in their combination is a novelty in modern studies of ecologicaleconomic processes. It is exhaustively taken into account that innovation is a complex process of transformation of newly obtained ideas and goals into an actual object of economic relations. At the same time, it was found that in the conditions of transformation of the modern Ukrainian economy began to manifest such features as frequent and unpredictable changes in demand due to the emergence of completely new needs, which can be satisfied only by qualitatively new, predominantly knowledge-intensive products. Therefore, there is an urgent need to restructure regional economies on a fundamentally new basis, which provides a real opportunity to reproduce the existing innovation potential, improve the innovation and technological level of all spheres of economic activity in the region and achieve a much higher degree of competitiveness. At the same time, given the significant role of innovation processes in improving and ensuring the proper environmental sustainability of regional economic systems, the definition of appropriate tasks, taking into account their characteristics, is a prerequisite for the effective management of natural resources of the country as a whole and its regions. Therefore, in European practice, the European Innovation Scoreboard (EIS), calculated by Eurostat, is used to determine the achieved level of regional innovation development. At the same time, the methodology used in its basis to assess the effectiveness of national research innovative projects is not without criticism. And one of the main criticisms was the absence of a conceptual or theoretical model of innovation. Simultaneously, this paper proposes a fundamentally new approach to determining the effectiveness of innovation in the hierarchical-regional dimension, which is based on the use of appropriate tools of multidimensional statistical analysis and statistics of the European Union (in particular, Eurostat) and the State Statistics Service of Ukraine. In addition, synchronously with their standardization, based on the obtained values of innovation levels in the regions, matrices were formed separately for incoming and outgoing regional innovation indices. Result. The achieved levels of innovativeness of Ukrainian regions in the context of ensuring appropriate environmental sustainability of their economic systems in the management of significantly limited natural resources were determined. Practical implications. Another real opportunity has arisen to significantly improve the management of the available natural resources of each region and the state as a whole in terms of ensuring the proper environmental sustainability of regional economic systems.
\end{abstract}

Key words: state, region, territory, environmental, sustainability, innovation indices, socio-economic development, innovation, innovations activity, natural resources, innovation process.

JEL Classification: R58

\footnotetext{
Corresponding author:

${ }^{1}$ Vasyl Stefanyk Precarpathian National University, Ukraine.

E-mail: zvarych2810@gmail.com

ORCID: https://orcid.org/0000-0003-2033-5054

${ }^{2}$ Vasyl Stefanyk Precarpathian National University, Ukraine.

E-mail: lena_zl@ukr.net

ORCID: https://orcid.org/0000-0002-5088-7565
} 


\section{Introduction}

The fact that the decisive innovative impact on the economic development of economic entities and their territories is carried out mainly at the expense of investment (both internal and external) is generally undeniable. However, the issues of analytical definition of such impact and the development of appropriate methods and models of their investment and innovation development are still open. Summing up the statements about investment and innovation policy, it is important to note that investment today are those economic resources that are directed not only to the expansion and modernization of production processes, but also on human capital (spending on education, research, training, etc.). It is becoming increasingly important at the present stage of economic development, since buildings and structures, machinery and equipment and, most importantly, the intellectual product as the main factor in modern economic development is mainly the result of human activity. The quality of human capital is also influenced by infrastructure, in particular its social component as a defining dominant providing subsystems of the regional economic sisterhood, so investment in social infrastructure, including environmental infrastructure, is also an investment in human capital. However, a new innovative form of investment (investment in innovation) has recently appeared in the economic literature, which is associated with the innovative direction of the world economy, aimed, in particular, at the economic use of available resources and the preservation of the environment for present and future generations. Therefore, the study of the impact of innovation on the environmental sustainability of economic systems in the context of the effective management of natural resources is of important theoretical and practical importance. In conclusion, it should be noted that further in this article the authors will proceed from the broadest interpretation of investment (it is the pooling of capital for income or social effect), and innovation is modern ideas and the latest product in the organization of labor, engineering, technology and other areas of scientific and social activity, based on the use of scientific advances, which are the end result of innovative activity.

\section{The impact of regional innovation on environmental sustainability}

Given the significant role played by innovation processes in the modern economy, the definition and consideration of their features is a prerequisite for sustainable development of the state as a whole and its regions in particular (Baula, Savosh, Liutak, 2017; Voloshchuk, Bogachuk, Ivanyshyn, 2020; Ganechko, Afanasiev, 2016; Strielina, Gromenkova, 2010; Peresada, 2020). Note that ecological sustainability is the ability of the agrarian landscape to resuspend changes under the influence of various external factors, to preserve the structure and features of functioning under the transformation of the natural environment and anthropogenic pressure (in particular, agricultural production). Therefore, environmental innovations play an extremely important role in ensuring the sustainable development of society and are the final eco-innovative product for the creation, use and implementation of environmentally oriented innovations, which are implemented in the form of environmental goods (products, works or services), technologies of their production, management methods at all stages of the production process and product sales, contributing to the development and growth of social and economic entities, ensuring resource and environmental safety, minimising the negative protection environment. Thus, the consideration of these issues in their totality is a novelty in research practice, so their study is tentatively relevant in the context of the relevant repeated research tasks, which are solved by systemic and synergetic approaches, methods of analysis and synthesis, induction and deduction, historical and comparative analysis, etc.

\section{European practice of defining regional innovation}

For this purpose, to determine the level of regional innovativeness it is proposed to use the European table of innovation development, calculated by Eurostat (European Innovation Scoreboard). However, the European Innovation Scoreboard (EIS) methodology for assessing the effectiveness of national research and innovation systems has not been criticized, which was fully justified (Baula, Savosh, Liutak, 2017). Thus, the 2017 EIS calculation for Ukraine was based not on 27 indicators, but on 18 (i.e., 2/3). Accordingly, comparing Ukraine and Poland, for example, on the basis of one combined indicator, for which all 27 indicators were used in calculating the EIS, is, according to the authors, generally incorrect. In 2016, the OECD criticized the EIS, particularly in (Methodology Report on European Innovation Scoreboard, 2017) for: the unbalanced use of INPUT and OUTPUT indicators; the calculation of performance indicators does not take into account structural differences between states; there is no conceptual and theoretical discussion. Relevant information in the EIS must be supplemented with contextual and qualitative information in order to formulate appropriate policies.

The Global Entrepreneurship Monitor (GEM) (The Global Entrepreneurship Monitor (GEM)) created an index of motivation that reflects the relative prevalence of entrepreneurs driven by improvement rather than necessity. Using GEM and EIS data, 
a public opinion survey of this index is presented, as its value, according to many scholars, is lower than that of national statistical services. Official statistical information on entrepreneurial activity is limited to data on registered enterprises, without distinguishing the reasons for founding a new enterprise (innovation opportunity or necessity). The motivational index is considered the best, taking into account the relationship between entrepreneurship and innovation (Zvarych, 2018; The Global Entrepreneurship Monitor (GEM); Bruno, Izsak and Hollanders, 2013; The Nomenclature of Territorial Units for Statistics).

The changes in the EIS measurement scheme compared to 2016 are as follows: the first is related to the regrouping of the innovative parameters of the EIS. The purpose of this regrouping is to better differentiate the conditions and investments in innovation, the activities of enterprises, and the impact of such measures on them. The second difference was the addition of another dimension to better reflect the environment in which businesses innovatively respond to changes in the environment, such as new business expansion opportunities or threats that typically arise from existing businesses as well as new members. The third is to break down all OUTPUT indicators to measure economic impact in two dimensions: measuring their impact on employment and estimating their impact on sales.

\section{Determination of regional innovativeness of territories of Ukraine}

Further, to determine the level of innovativeness of the regions of Ukraine it is proposed to use, on the one hand, a structural measure of development as a tool of multivariate statistical analysis, and on the other hand, the EIS 2017 indicators. In the process of discussing the level of regional innovation based on the analysis, one of them is the interpretation of regional innovation as a proportional relationship between innovation indicators such as INPUT and OUTPUT (Zvarych, 2018). Based on this approach, it is proposed to determine the effectiveness of regional innovation. To do this it is necessary to perform the following steps: to form statistical matrices based on regional innovation factors separately by INPUT and OUTPUT types; to determine the degree of innovativeness of each region of Ukraine; to evaluate the effectiveness of innovation in a hierarchical context.

Definition of statistical matrices based on regional factors of innovativeness separately by INPUT and OUTPUT types. The European Innovation Scoreboard highlights the following spaces: knowledge creation and entrepreneurship; investment; innovation; and impact. Selected spaces can be grouped into appropriate matrices according to the following hierarchical or indicator characteristics in terms of: national; regions in each state; meters of each INPUT group; meters of each OUTPUT group. According to their characteristics, regional innovation indicators were grouped into INPUT and OUTPUT types and the corresponding national statistical calculation indicators and corresponding units of measurement were selected. The next step is to construct a measure of regional innovation such as INPUT and OUTPUT. The construction of such an index of regional innovation of the INPUT type is based on partial indices, which are defined for two groups of indicators: knowledge creation and entrepreneurship; investment. A partial INPUTtype index of regional innovation for each group of measures using data for all regions in all countries is the arithmetic average of the normalized values of each indicator for each region in each country. The normalized value is defined as the ratio of the deviation of the indicator from the minimum in the state to the deviation of the maximum and minimum values in the state. Thus, we get a value, the range of change of which is a value from 0 to 1 . The construction of such an index of regional innovations of the OUTPUT type is based on partial indices for certain groups of indicators: innovation; impact. The principle of calculation of partial indices is the same as for INPUT indices. The constructed partial indices are used to build regional innovation indices INPUT and OUTPUT. These indices by analogy are arithmetic averages of their partial indices. Thus, their values will also change in the interval $[0,1]$. Since all EIS indicators are stimulators, the interpretation of the indices is as follows: closer to 1 the value of the index shows a higher level of INPUT or OUTPUT type innovation. These indices allow us to rank regions according to their level of innovation on a national scale, taking into account the costs of innovation and the effects of innovation (Methodology Report on European Innovation Scoreboard 2017). Semantic interpretation of the effectiveness of regional innovation requires refinement of the procedure of classification of regions, taking into account the chosen method of correlation of INPUT and OUTPUT indices. The generalization will make it possible to determine the level of regional innovation efficiency in the region. The proposed measure of innovation efficiency in the region will allow to determine the degree of innovation and state efficiency, in fact, at the national level. The last step is the construction of a measure of the effectiveness of innovation of the country in a hierarchical regional context, the measurement of which in a hierarchical interpretation takes into account the influence of the region on the state level in the field of innovation. Regarding the results from the implementation of innovations, the leading positions are occupied by Kharkiv region, Kyiv and Sevastopol (Figure 1). 


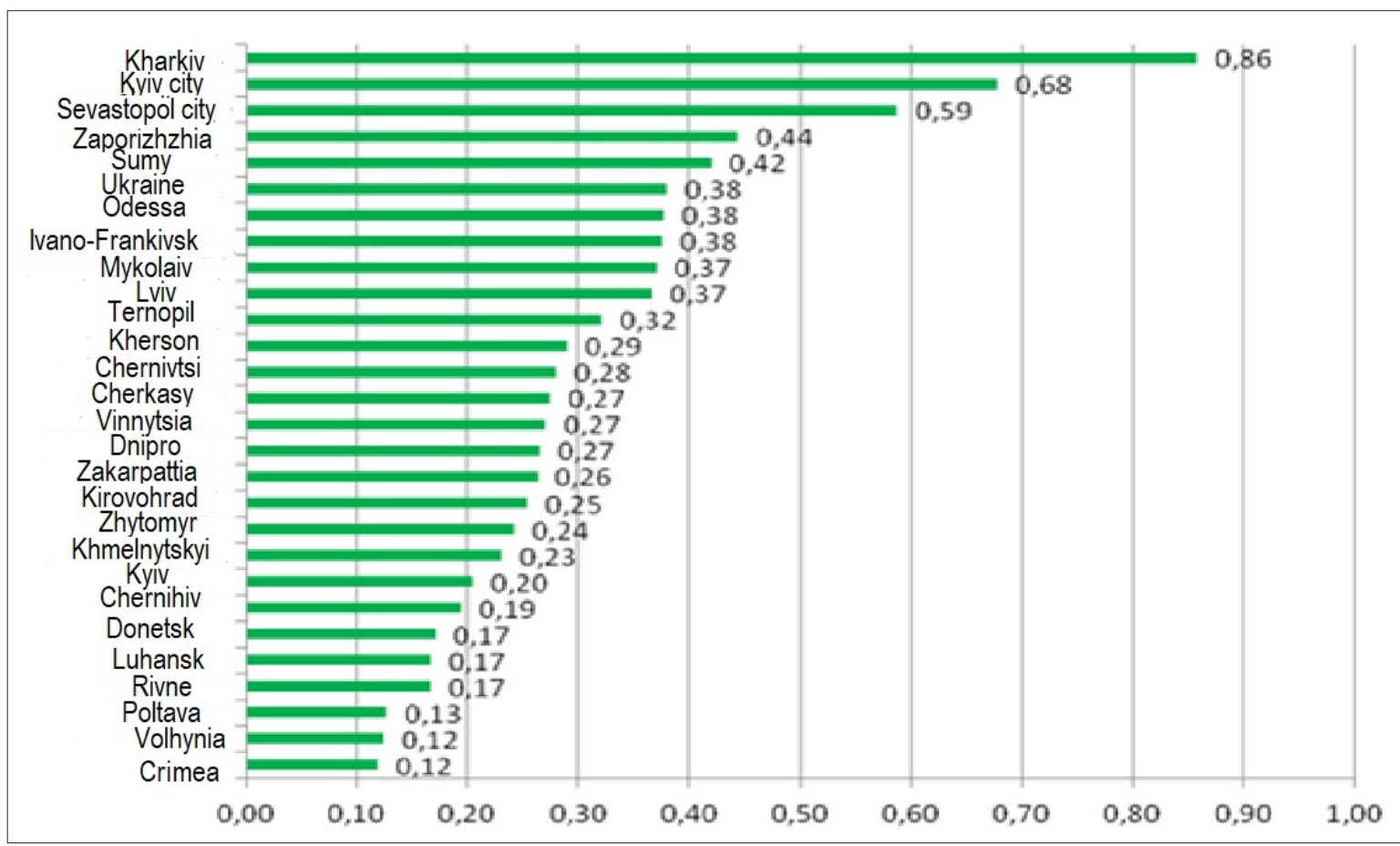

Figure 1. Average values of OUTPUT type innovation indices for the period 2010-2020

Source: (Zvarych, 2018)

Zaporizhzhia, Sumy, Odessa, Ivano-Frankivsk, Mykolaiv and Lviv regions have slightly higher values compared to the INPUT index. This indicates that innovation, in addition to financial, economic, and educational factors, has a significant impact on other factors not reflected in the EIS. The effectiveness of innovation depends on technological (especially the focus on the development of modern technologies and market needs for new products), organizational and managerial (state of management; ability to innovate, change, restructuring; regional management structure) and, especially, social and psychological (attitude, expectations and reaction to the introduction of innovation) factors (Zvarych, 2018).

The proposed measure of the effectiveness of regional innovation provides a real opportunity to determine the measure of the effectiveness of innovation of the state (MEIS). Table 1 shows the MEIS estimates for different values.

As can be seen from Table 1, the values of the measure of innovation effectiveness in the national context belong to the numerical range $[0,01 ; 1]$. Its values, which are closer to the minimum, mean that the country has a weak position in terms of the effectiveness of innovation in a regional context, and values closer to 1 indicate the high effectiveness of its innovation in terms of territories (Zvarych, 2018).

\section{Conclusions}

Thus, based on the analysis of modern assessment of innovation, a methodological approach to determine the degree of innovation in a hierarchical regional context, drawing on the tools of multivariate statistical analysis, has been developed. The analysis of innovation in the regions of Ukraine on the basis of the proposed methodological approach led to the following conclusions: the proposed EIS does not contain a basic model of innovation, which would allow to justify the choice of innovative measurements and indicators and reflect the reasons that can be affected by innovation policy; the use of a single composite indicator and rating table does not allow

Table 1

Measuring the Effectiveness of Innovation in a National Context (MEIS)

\begin{tabular}{|c|c|c|c|c|c|c|}
\hline & 2010 & 2012 & 2014 & 2015 & 2016 & 2020 \\
\hline$\alpha=0,01$ & 0,89 & 0,96 & 0,96 & 0,92 & 0,92 & 0,96 \\
\hline$\alpha=0,2$ & 0,87 & 0,90 & 0,93 & 0,89 & 0,89 & 0,93 \\
\hline$\alpha=0,4$ & 0,80 & 0,83 & 0,86 & 0,85 & 0,82 & 0,87 \\
\hline$\alpha=0,6$ & 0,57 & 0,70 & 0,60 & 0,82 & 0,78 & 0,70 \\
\hline$\alpha=0,8$ & 0,30 & 0,43 & 0,35 & 0,60 & 0,53 & 0,43 \\
\hline$\alpha=1$ & 0,10 & 0,10 & 0,11 & 0,11 & 0,11 & 0,10 \\
\hline
\end{tabular}


us to track the complexity of the innovation process; too many indicators determine innovation in hightech industries. This shifts innovation performance in favor of those countries that specialize in high-tech industries, particularly high-tech manufacturing; many indices are highly correlated and thus can cover and measure the same aspect of the innovation process. Most indicators are not available for Ukrainian statistics, so the distortion of data may jeopardize the reliability and accuracy of comparisons of Ukraine's innovation performance with other countries. At the same time, a logical conclusion can be drawn about the lack of regional and state policy to stimulate and support innovation, because the costs are too minuscule, especially on a regional scale. Meanwhile, to determine the achieved degree of efficiency of innovation in the national context, it is proposed to interpret the use of indicator as a multiplier of innovation in the regions. Its importance directly determines the position of the state on the effectiveness of innovation in the regional context, and can therefore serve as a guide for national policy on this important issue.

\section{References:}

Ganechko, I. G., \& Afanasiev, K. M. (2016). Innovation activity in Ukraine: tendencies and problems of development. Bulletin of Uzhgorod nat. un-ty. Economics series, vol. 1(47), issue 1, pp. 189-193.

Baula, O. V., Savosh, L. V., \& Liutak, O. M. (2017). Prospects for innovative development of Ukraine's economy in the context of the EU innovation scoreboard. Bulletin of Uzhgorod nat. un-ty. Economics series, vol. 12, part 1, pp. 24-28.

Voloshchuk, Ju. O., Bogachuk, S. V., \& Ivanyshyn, O. V. (2020). Principles of ensuring innovative development of enterprises. Innovative economy, vol. 1-2, pp. 73-78.

Peresada, A. A. (2020). Investment process management. Kyiv: Libra, 472 p.

Strelina, O. M., \& Gromenkova, V. A. (2010). Development of innovative technologies in the conditions of integration of Ukraine into the international economic space. Bulletin Khmelnytskyi nat. un-ty, no. 5, issue 4, pp. 318-322.

European Innovation Scoreboard. Available at: http://www.ec.europa.eu (accessed 17 December 2021).

Zvarych, O. I. (2018). Innovation indices of INPUT and OUTPUT regions. Current problems of modelling and management of socio-economic systems in the context of globalization. Mater. International. scient.-practic. conf. (Drohobych, May 11). Drohobych, pp. 147-151.

Methodology Report on European Innovation Scoreboard 2017. Available at: http://www.ec.europa.eu (accessed 17 December 2021).

The Global Entrepreneurship Monitor (GEM). Available at: http://www.gemconsortium.org (accessed 17 December 2021).

Bruno, N., Izsak, K., \& Hollanders, H. (2013). New ways of measuring innovation, IUS Exploratory reports. Brussels: European Commission, 2013. Available at: http://www.hollanders.unumerit.nl/EIS/New\%20ways\%20 of\%20\%.measuring.innovation.pdf (accessed 17 December 2021).

The Nomenclature of Territorial Units for Statistics. Available at: http://www.ec.europa.eu/eurostat/web/nuts (accessed 17 December 2021). 